\title{
Spray-Printed and Self-Assembled Honeycomb Electrodes of Silicon- Decorated Carbon Nanofibers for Li-Ion Batteries
}

\author{
Sang Ho Lee, *(i) Kexue Li, Chun Huang, Jack D. Evans, and Patrick S. Grant \\ Department of Materials, University of Oxford, Oxford OX1 3PH, U.K. \\ Supporting Information
}

ABSTRACT: Directional, micron-scale honeycomb pores in Li-ion battery electrodes were fabricated using a layer-by-layer, self-assembly approach based on spray-printing of carbon nanofibers. By controlling the drying behavior of each printed electrode layer through optimization of (i) the volume ratio of fugitive bisolvent carriers in the suspension and (ii) the substrate temperature during printing, self-assembled, honeycomb pore channels through the electrode were created spontaneously and reliably on current collector areas larger than $20 \mathrm{~cm} \times 15 \mathrm{~cm}$. The honeycomb pore structure promoted efficient Li-ion dynamics at high charge/discharge current densities. Incorporating an optimum fraction (2.5 wt
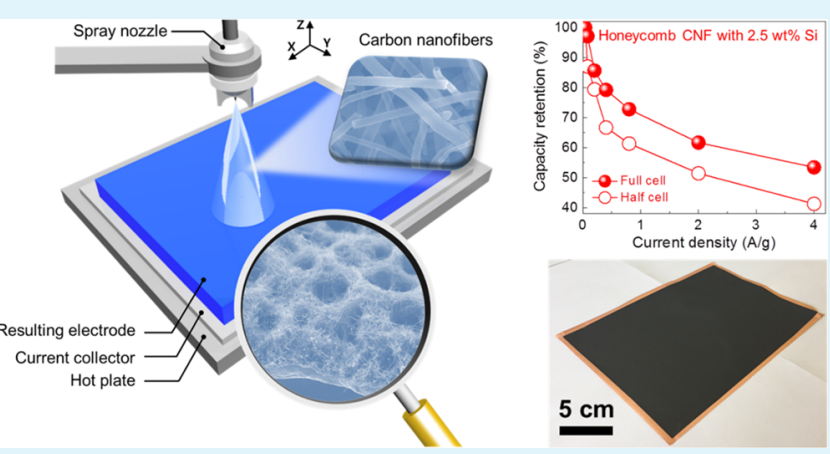
$\%)$ of high-energy-density Si particulate into the honeycomb electrodes provided a 4-fold increase in deliverable discharge capacity at $8000 \mathrm{~mA} / \mathrm{g}$. The spray-printed, honeycomb pore electrodes were then investigated as negative electrodes coupled with similar spray-printed $\mathrm{LiFePO}_{4}$ positive electrodes in a full $\mathrm{Li}$-ion cell configuration, providing an approximately $50 \%$ improvement in rate capacity retention over half-cell configurations of identical electrodes at $4000 \mathrm{~mA} / \mathrm{g}$.

KEYWORDS: self-assembly, honeycomb pattern, spray-printing, carbon nanofiber, silicon particle, Li-ion battery

\section{INTRODUCTION}

Porous or hollow frameworks and particulate materials are useful in a range of applications, including photovoltaics, ${ }^{1,2}$ electronics, ${ }^{3,4}$ sensing, ${ }^{5,6}$ biologics, ${ }^{7,8}$ electrocatalysis, ${ }^{9,10}$ and energy storage, ${ }^{11,12}$ where maximizing mass transport behavior (e.g., ion mobility) and active surface area is desired. Porous and hollow structures have been studied extensively for rechargeable Li-ion battery (LIB) technologies where interconnected pores within a LIB anode or cathode are essential for effective ion diffusion and "deep" penetration to all active sites within the electrode; ${ }^{13,14}$ these relatively open structures may also help to mitigate the mechanical strain of repeated lithiation/delithiation processes. ${ }^{15,16}$ The associated high active area may contribute positively to fast electrode charge/discharge kinetics but may also be detrimental where a passivating solid electrolyte interphase (SEI) is formed in the first few charge/discharge cycles, irreversibly consuming $\mathrm{Li}$ ions, or especially where a nonpassivating SEI is formed continuously. Although high porosity active materials and engineered porosity at the electrode scale may promote high capacity per unit weight of active materials, they also usually undermine volumetric capacity of resulting cells and battery packs, which is undesirable from a technological point of view.

A high electrode surface area can be achieved by using an active material with fine-scale or even nanoscale porosity. For example, a wide range of high surface area, hollow particles and tube structures at the nanoscale have been proposed and successfully demonstrated in LIB electrodes based on hydro- thermal, sol-gel, and sacrificial template methods. ${ }^{17-20}$ Recently, yolk-shell designs for various electrode materials, including $\mathrm{TiO}_{2}$, Si and others have been developed with the intention of improving both high-rate capability and charge/ discharge cycle stability in a LIB configuration. ${ }^{21-24}$ At the electrode manufacture stage, these high-specific-surface area materials are formed into an LIB electrode using slurry casting, which is the dominant and most productive electrode fabrication method. ${ }^{25-27}$ A composite slurry, including carbon-based conductivity enhancers and polymeric binders, in an aqueous or nonaqueous solvent, is cast onto a current collector via a doctor blade or slot-die process and then sequentially dried to produce a robust, well-adhered composite coating over large areas, including using semicontinuous or near-continuous roll-to-roll operations. ${ }^{28,29}$ However, the intrinsic electrochemical performance of the as-synthesized materials is usually restricted or inhibited in the slurry cast electrode microstructure because the binder partly obscures some of the active surface, and when reasonable coating thicknesses ( $50 \mu \mathrm{m}$ and above) are used to achieve practically usable volumetric capacities, the electrode porosity is so tortuous that Li-ion mobility is restricted at higher charge/ discharge rates and capacity fades.

Received: September 1, 2018

Accepted: December 6, 2018

Published: December 6, 2018 
To address these constraints, new approaches to produce micron-scale porous structures with more efficient integration of active materials, conductivity enhancers, and binders have been proposed. For example, template-assisted methods offer excellent control over pore size and morphology but fabricating and then removing the fine-scale featured sacrificial templates can cause problems for cost and scalability and volumetric capacity tends to be unhelpfully low. ${ }^{30-32}$ Lithographic technologies based on ultraviolet light irradiation and/ or ion etching processes allow pore fraction, shape, and alignment to be controlled with micron resolution but require inherently high-cost fabrication apparatus. ${ }^{33-35}$ Thus, there remains an opportunity for manufacturing approaches that allow improved and more flexible micron-scale pore engineering in LIB electrodes and that have the potential for costeffective scalability.

In this paper, self-assembled, fibrous honeycomb electrodes were readily manufactured directly onto current collectors via a spray-printing approach. The process is demonstrated for otherwise hard-to-process hollow carbon nanofiber (CNF)based electrodes that were then investigated for LIB applications, first in half-cells and then in full cells using optimized versions of a honeycomb CNF-based anode and a spray-printed $\mathrm{LiFePO}_{4}$ (LFP)-based cathode. Optimization of the drying behavior of the printed electrode layers, in particular, the formulation of the bisolvent carrier used in the ink suspension and the substrate temperature during sprayprinting, ensured that the honeycomb network of micron-scale through-thickness pore channels formed reliably over large areas. Electrochemical testing showed that the honeycomb pores promoted Li-ion mobility and excellent gravimetric and volumetric capacity at high charge/discharge rate conditions. To boost the specific capacity of the honeycomb CNF electrodes further, an optimum $2.5 \mathrm{wt} \%$ fraction of highcapacity $\mathrm{Si}$ nanoparticles was grafted onto the CNFs, increasing the discharge capacity at the highest current density of $8000 \mathrm{~mA} / \mathrm{g}$ by a factor of four and giving a $65 \%$ improvement in the sustained discharge capacity after 300 cycles at $400 \mathrm{~mA} / \mathrm{g}$. Spray-printed CNF-based anodes were coupled with spray-printed LFP-based cathodes in a full-cell configuration where the honeycomb CNF $+2.5 \mathrm{wt} \% \mathrm{Si}$ outperformed an identical honeycomb CNF-only equivalent in rate capability, cycle stability, and deliverable discharge capacity. We show that the principal electrochemical benefit of the bottom-up spontaneous self-assembly of the active materials into honeycomb electrodes is to sustain capacity into the high current density region. The honeycomb structure allows the intrinsic electrochemical performance of well-known but difficult-to-process materials to be more readily realized.

\section{RESULTS AND DISCUSSION}

Figure 1 depicts a schematic of the spray-printing of honeycomb electrodes directly onto a large area current collector, typically $>20 \mathrm{~cm} \times 15 \mathrm{~cm}$. For the successful selfassembly of the directional pore structure in each sprayed layer and from layer to layer, the suspension containing active materials and inactive components must be optimized for (i) appropriate rheological properties to enable facile pumping, from the reservoir to the atomizing spray head; (ii) stable atomization without pulsing; and (iii) appropriate drying behavior to propagate the honeycomb structure without excessive fugitive liquid buildup and resuspension of predeposited material. In this case, CNF-based active material,

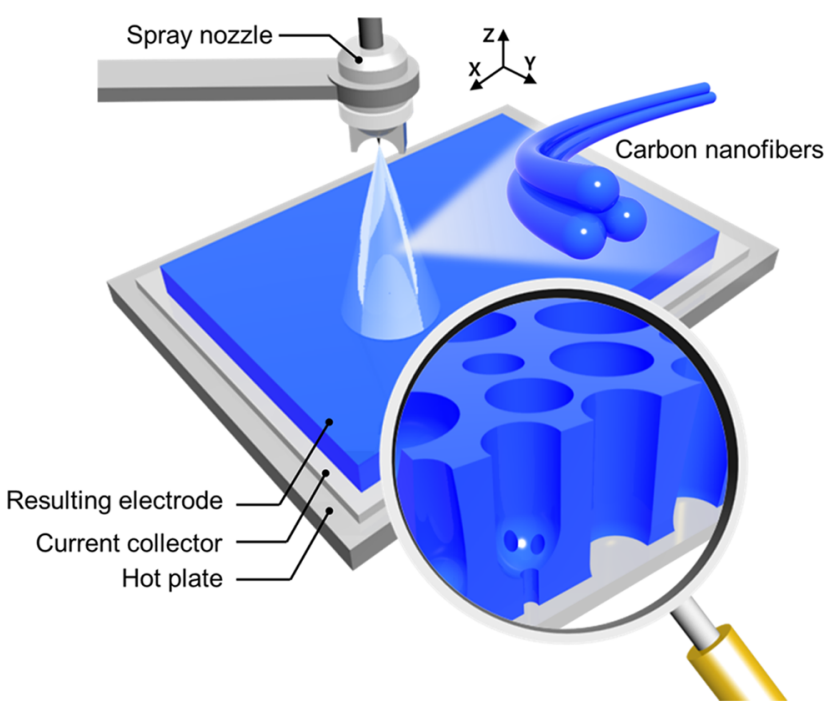

Figure 1. Graphical illustration of the spray-printing layer-by-layer self-assembly of the honeycomb electrode directly onto a heated current collector using a bisolvent suspension of CNFs. The magnified cartoon shows an idealized morphology of the directional micron-scale pores comprising the honeycomb pattern.

conductivity enhancer, and a polymeric binder in a controlled mass ratio were suspended in a fugitive bisolvent liquid carrier of deionized (DI) water and isopropyl alcohol (IPA). The DI/ IPA ratio was optimized to provide both a repeatable suspension without any sedimentation and two-stage drying behavior of the bisolvent to drive the self-assembly of the honeycomb structure. ${ }^{36}$

The suspensions were atomized using compressed air in a spray nozzle that moved in a preprogrammed zigzag pattern in the $x$ and $y$ plane with a fixed $z$ spray distance to the current collector for multiple cycles. The heated current collector was set to a temperature higher than the boiling point of the bisolvents to ensure rapid in situ drying and a micron-scale through-thickness honeycomb pore structure, as depicted in the magnified cartoon of Figure 1.

Figure 2 presents scanning electron microscopy (SEM) images of a self-assembled, honeycomb porous electrode, fabricated by layer-by-layer spray-printing using CNFs of 100$200 \mathrm{~nm}$ diameter (see Figure $\mathrm{S} 1$ in the Supporting Information). Pores of $20 \pm 8 \mu \mathrm{m}$ diameter were separated by interwoven CNF fibrous honeycomb cell "walls" of thickness of $10 \pm 5 \mu \mathrm{m}$, as shown in the electrode plan view image in Figure $2 \mathrm{a}$. Figure $2 \mathrm{~b}$ shows a magnified view looking "down" through a pore showing smaller pores $(2 \pm 1 \mu \mathrm{m})$, suggesting that adjacent, smaller pores had combined and merged into the larger pore as the deposition progressed layer by layer. ${ }^{36,37}$ The electrode cross section in Figure $2 \mathrm{c}$ reveals the intended through-thickness $(20 \mu \mathrm{m})$ pore channels from the electrode surface to the current collector, as highlighted by the yellow dotted line, with thicknesses from 10 to $80 \mu \mathrm{m}$ readily available by tuning the number of spray scan cycles. ${ }^{36} \mathrm{~A}$ magnified electrode cross-sectional view in Figure 2d, obtained using focused ion beam (FIB) milling, shows more detail of the interior of the fibrous honeycomb structure, supporting the intent that the micron-scale pores were interconnected throughout the electrode.

For suspension stability, the DI/IPA ratio was critical because although the polymeric binder (carboxymethyl 

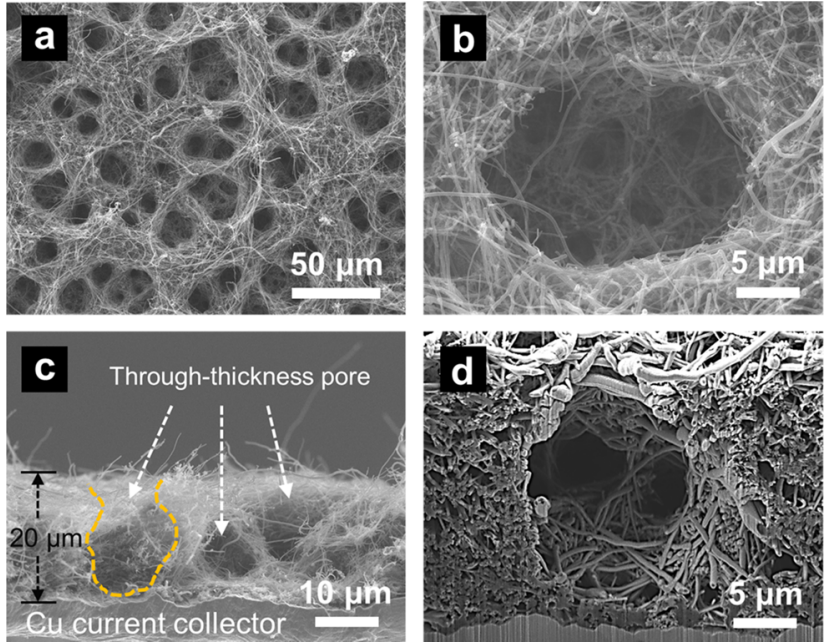

Figure 2. (a) SEM image of the surface of the spray-printed fibrous honeycomb CNF electrode. (b) Magnified image of the micron-scale pore region. (c) Electrode cross section showing directional pore channels, as highlighted by the yellow dotted line. (d) FIB cross section of the fibrous honeycomb structure.

cellulose, CMC) dissolved in DI water only, the CNFs and carbon conductivity enhancer (Super P, SP) were dispersed preferentially in IPA. Figure 3 shows the CNF-based electrode morphology as a function of DI/IPA volume ratios of 100:0, 70:30, 50:50, 30:70, and 0:100, with the bar graphs in each inset of Figure 3a-e indicating the different volume ratios of DI water (blue) and IPA (red). For the suspension formulated with DI water only, the plan view in Figure $3 a$ and the corresponding tilted view in Figure $3 \mathrm{f}$ show almost no deposition of the active material, implying a lack of suspension stability. Although the suspension with IPA only (Figure 3e,j) showed a slightly improved deposition yield, the electrode was again too thin and too poorly adhered to the current collector for use, which was attributed to a lack of function of the CMC binder that did not disperse in the IPA-only suspension. For DI/IPA mixtures of 70:30 and 30:70, the suspensions were noticeably more stable without any obvious sedimentation and the deposition efficiency increased markedly. However, no reliably reproducible micron-scale pore structure was formed, as shown in Figures 3b,g, and 3d,i. At a 50:50 DI/IPA volume ratio (Figures $3 \mathrm{c}, \mathrm{h}$ ), micron-scale through-thickness honeycomb pores were spontaneously formed and reproduced readily from experiment to experiment.

The effect of the substrate temperature was investigated using 50:50 DI/IPA suspensions at following conditions: (i) $60{ }^{\circ} \mathrm{C}$ (lower than the boiling point of both DI water and IPA), (ii) $90{ }^{\circ} \mathrm{C}$ (higher than the boiling point of IPA at $\sim 80$ ${ }^{\circ} \mathrm{C}$ but lower than DI water), and (iii) $120^{\circ} \mathrm{C}$ (higher than the boiling point of both DI water and IPA), as indicated in the bar graph in Figure 4a. At 60 and $90{ }^{\circ} \mathrm{C}$, the resulting electrodes had an excellent deposition efficiency but no micron-scale pores, as shown in the SEM images of the electrode surface in Figure 4 b,c. At $120{ }^{\circ} \mathrm{C}$, the electrodes spontaneously assembled into a fibrous honeycomb morphology (Figure $4 \mathrm{~d}$ ), showing that rapid, effective evaporation of the fugitive bisolvent, first the IPA then the DI water, was required. A similar self-assembly of the active component in electrochemical electrodes using a layer-by-layer bisolvent approach has been also achieved for coral-like $\mathrm{TiO}_{2}(\mathrm{~B})$ electrodes in a previous work. ${ }^{36}$
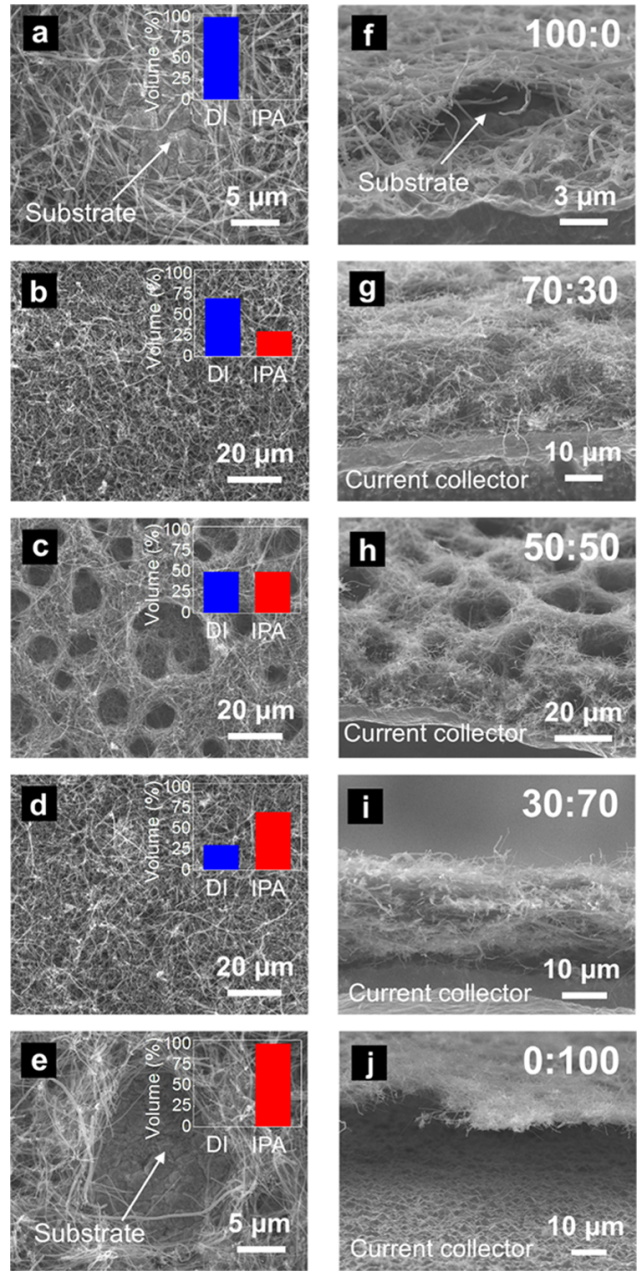

Figure 3. Plan view SEM images of the surface of spray-printed CNF electrodes as a function of the volume ratio of DI water to IPA: (a) 100:0, (b) 70:30, (c) 50:50, (d) 30:70, and (e) 0:100. The bar graph in each inset shows the change of the DI/IPA volume ratio. $(f-j)$ Corresponding electrode cross sections.
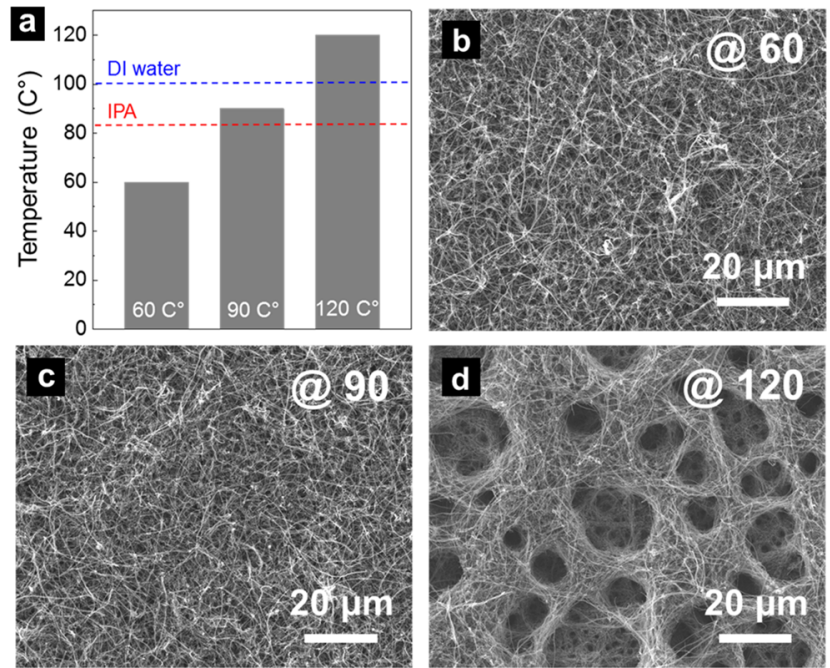

Figure 4. (a) Substrate temperatures compared with the boiling points of DI water and IPA. Plan view SEM images of the surface of spray-printed $\mathrm{CNF}$ electrodes as a function of substrate temperature: (b) $60{ }^{\circ} \mathrm{C}$, (c) $90{ }^{\circ} \mathrm{C}$, and (d) $120{ }^{\circ} \mathrm{C}$. 

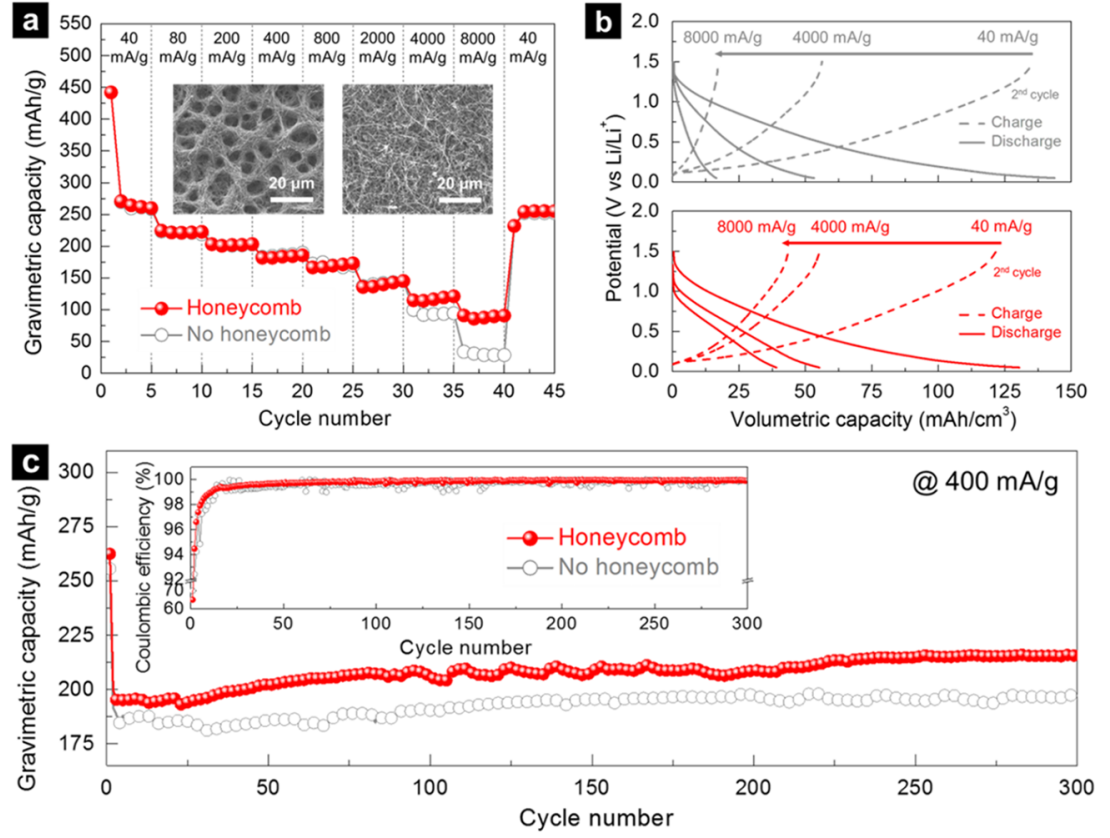

Figure 5. (a) Discharge capacity profiles of the spray-printed CNF electrodes with and without the honeycomb structure at various charge/ discharge current densities in the potential range of $0.05-1.5 \mathrm{~V}\left(\mathrm{vs} \mathrm{Li} / \mathrm{Li}^{+}\right)$. SEM images in the inset show the surface of the spray-printed CNF electrodes with and without the honeycomb pattern. (b) Charge/discharge plots in the potential range of $0.05-1.5 \mathrm{~V}\left(\mathrm{vs} \mathrm{Li} / \mathrm{Li}{ }^{+}\right)$. (c) $\mathrm{Galvanostatic}$ discharge profiles in the voltage window of $0.05-1.5 \mathrm{~V}\left(\mathrm{vs} \mathrm{Li} / \mathrm{Li}^{+}\right)$at $400 \mathrm{~mA} / \mathrm{g}$. The inset shows the corresponding coulombic efficiency.

To investigate any faradaic charge storage benefits of the honeycomb structure in an LIB configuration, the electrochemical performance of spray-printed honeycomb CNF electrodes formulated with the optimum 50:50 DI/IPA ratio was compared with that of nonhoneycomb but otherwise identical CNF electrodes formed using a 70:30 DI/IPA ratio, which is shown in the inset SEM images in Figure 5a, emphasizing the different morphologies of the two electrodes, each $20 \mu \mathrm{m}$ thick (see Table 1). Figure 5a also shows the

Table 1. Summary of the Spray-Printed CNF Electrodes with and without the Honeycomb Pattern

\begin{tabular}{lccc}
\multicolumn{1}{c}{ sample } & $\begin{array}{c}\text { formulation } \\
(\mathrm{CNF} / \mathrm{SP} / \mathrm{CMC})\end{array}$ & $\begin{array}{c}\text { thickness } \\
(\mu \mathrm{m})\end{array}$ & $\begin{array}{c}\text { mass loading } \\
\left(\mathrm{mg} / \mathrm{cm}^{2}\right)\end{array}$ \\
\hline honeycomb & $80: 10: 10$ & $20 \pm 3$ & $0.95 \pm 0.04$ \\
no & $80: 10: 10$ & $20 \pm 4$ & $1.09 \pm 0.05$ \\
honeycomb & & &
\end{tabular}

deliverable discharge capacity profiles for the two electrodes at charge/discharge current densities of $40-8000 \mathrm{~mA} / \mathrm{g}$. In the 1 st cycle, the very high discharge capacity of all electrodes was likely associated with side reactions, including SEI formation, which is typical of CNFs. ${ }^{38,39}$ In subsequent cycles and at relatively low current density $(40-2000 \mathrm{~mA} / \mathrm{g})$, the electrodes had almost identical discharge capacities, implying little benefit of the micron-scale pores since there was sufficient time for ion transport to all active sites in both electrodes. However, a difference in deliverable capacity developed on further increase in the current density $(\geq 4000 \mathrm{~mA} / \mathrm{g})$, with the honeycomb electrode delivering $\sim 100 \mathrm{mAh} / \mathrm{g}$ at $8000 \mathrm{~mA} / \mathrm{g}$ that was three times that of the identical electrode without the honeycomb structure, outperforming conventional graphite electrodes (anodes) at similar rates. ${ }^{40-42}$ Thus, despite the initial high reactivity and relative low electrode density, the honeycomb structure delivered significant benefits in the high C-rate region.

The self-assembled honeycomb electrode also had a benefit in terms of volumetric capacity at increasing charge/discharge conditions, as shown in Figure $5 b$, wherein volumetric capacity was calculated by normalizing the gravimetric capacity by the electrode mass loading and thickness, as given in Table 1 . At a relatively low rate of $40 \mathrm{~mA} / \mathrm{g}$, the honeycomb CNF electrode had a slightly lower volumetric capacity, implying that the through-thickness pore channels contributed only parasitic, wasted pore volume. However, at 4000 and $8000 \mathrm{~mA} / \mathrm{g}$, the honeycomb electrode volumetric performance was significantly better. Figure $5 \mathrm{c}$ presents the galvanostatic discharge behavior of both electrodes at a constant charge/discharge current density of $400 \mathrm{~mA} / \mathrm{g}$. As repeated charge/discharge cycles progressed to 300 cycles, discharge capacities of both sprayprinted CNF electrodes with and without the honeycomb increased progressively, as previously reported for CNF-based electrodes. ${ }^{43-45}$ This behavior was ascribed to the progressive activation of ion storage sites embedded between the interconnected CNFs or the partially reversible formation and dissolution of the passivated SEI layers on the CNFs. After 300 cycles, the honeycomb electrode had a discharge capacity of $\sim 210 \mathrm{mAh} / \mathrm{g}$ compared with $\sim 196 \mathrm{mAh} / \mathrm{g}$ for the identical electrode without the honeycomb. Except for the first few charge/discharge cycles associated with side reactions including SEI formation, all spray-printed CNF electrodes had a coulombic efficiency of almost $100 \%$ up to the $300^{\text {th }}$ cycle (inset of Figure 5c).

The effective Li-ion diffusion coefficient in each electrode was estimated from cyclic voltammetry $(\mathrm{CV})$ measurements over scan rates in the range of $0.05-1.0 \mathrm{mV} / \mathrm{s}$, which is a common approach to assess overall electrode kinetics at increasing rates. ${ }^{36,46,47}$ In the CV profiles for the spray-printed CNF electrodes with and without the honeycomb pore (Figure 

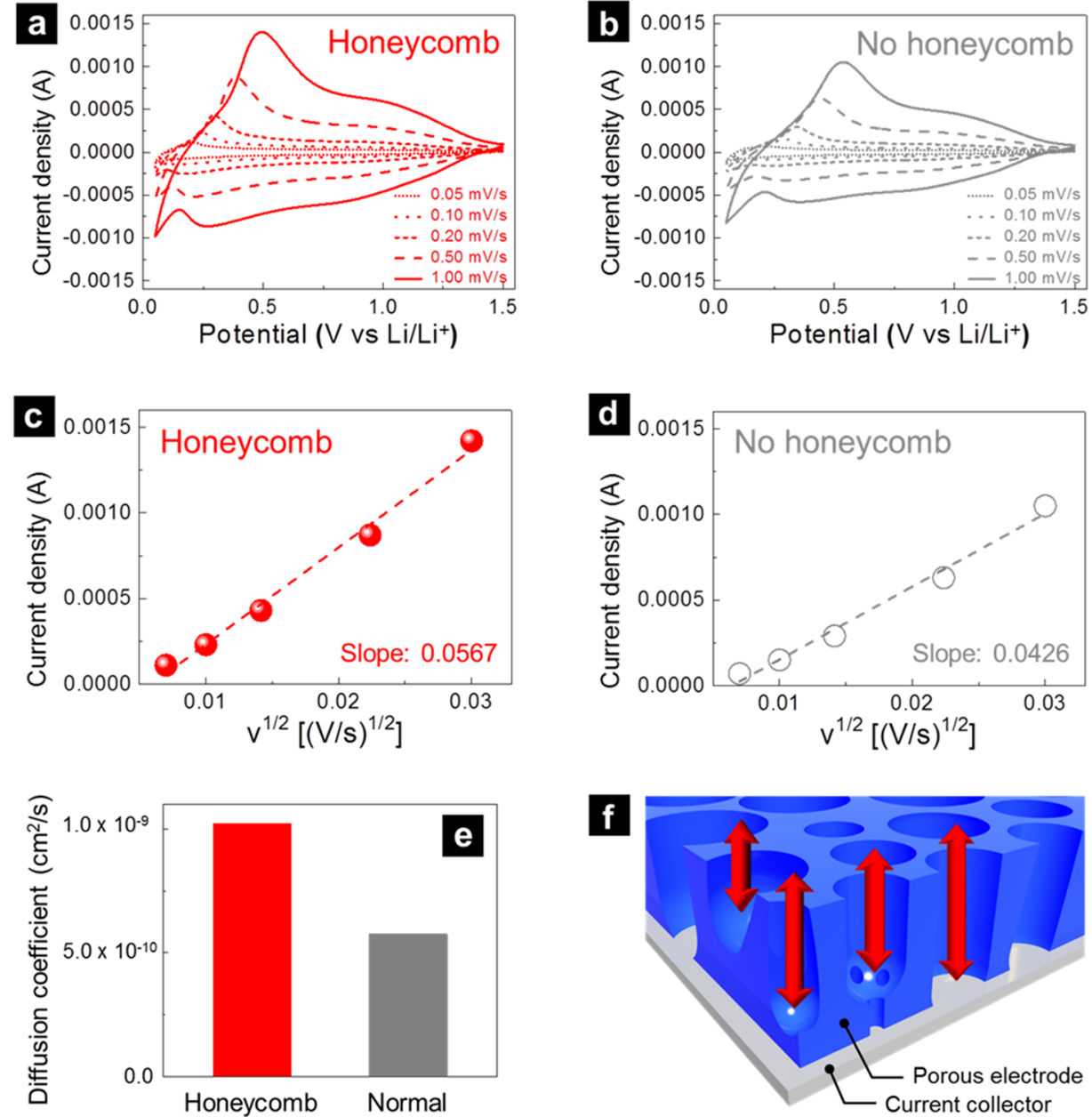

Figure 6. CV profiles of the spray-printed CNF electrodes (a) with and (b) without the honeycomb pore structure at various scan rates of $0.05-1.0$ $\mathrm{mV} / \mathrm{s}$ in the potential range of $0.05-1.5 \mathrm{~V}\left(\mathrm{vs} \mathrm{Li} / \mathrm{Li}^{+}\right)$. Relationship between the anodic peak at around $0.5 \mathrm{~V}$ and the square root of the scan rate for the spray-printed CNF electrodes (c) with and (d) without the honeycomb pattern. (e) Comparison of the effective Li-ion coefficients. (f) Schematic diagram of the ideal penetration and directional diffusion paths of $\mathrm{Li}$ ions through the pores "deep" into the electrode.

$6 a, b)$, there were a pair of anodic/cathodic peaks at approximately 0.5 and $0.2 \mathrm{~V}$, respectively, associated with the lithiation/delithiation reaction of graphite. ${ }^{48,49}$ As the scan rate increased progressively up to $1.0 \mathrm{mV} / \mathrm{s}$, the anodic/cathodic peak current density increased correspondingly but the relative peak intensity changes were different, implying a difference in the diffusion kinetics between the electrodes. Figure $6 c, d$ shows plots of the anodic peak current density as a function of the square root of the scan rate for the CNF electrodes with and without the honeycomb structure, respectively. In both cases, the peak current density was a good fit to the square root of the scan rate and the Li-ion diffusion coefficient could then be estimated using the Randles-Sevcik equation ${ }^{36,46,47}$

$$
I_{\mathrm{p}}=0.4463 n \mathrm{FAC}_{0}\left(n \mathrm{Fv} D_{\mathrm{Li}} / R T\right)^{1 / 2}
$$

where $I_{\mathrm{p}}$ is the peak current [A], $n$ is the number of electrons transferred, $F$ is the Faraday constant $[\mathrm{C} / \mathrm{mol}], A$ is the electrode area $\left[\mathrm{cm}^{2}\right], C_{0}$ is the molar concentration of the $\mathrm{Li}$ ions in the electrode $\left[\mathrm{mol} / \mathrm{cm}^{3}\right], v$ is the scan rate $[\mathrm{V} / \mathrm{s}], D_{\mathrm{Li}}$ is the Li-ion diffusion coefficient $\left[\mathrm{cm}^{2} / \mathrm{s}\right], R$ is the gas constant $[\mathrm{J} /(\mathrm{K} \cdot \mathrm{mol})]$, and $T$ is the temperature $[\mathrm{K}]$. The value of Li-ion diffusion coefficient is the net effect of various electrode phenomena, including Li-ion diffusion/transport and insertion/deinsertion. From the best fit slope of the $I_{\mathrm{p}}$-versus- $v^{1 / 2}$ plots (Figure $6 \mathrm{c}, \mathrm{d}$ ), the honeycomb electrode was estimated to have a diffusion coefficient of $\sim 1.0 \times 10^{-9}$ that was almost 2 times that of the identical electrode without the honeycomb $\left(\sim 5.8 \times 10^{-10} \mathrm{~cm}^{2} / \mathrm{s}\right)$ (see the comparative bar graph in Figure $6 \mathrm{e})$. Given that the materials are identical in the two electrodes, it is a reasonable assumption that, to a first order approximation, any change in performance is primarily due to a change in the microstructure. This supports that the honeycomb structure led to improved electrode charge/ discharge dynamics through promoting ion mobility, as described in the schematic illustration in Figure 6f, helping to sustain rate performance at fast charge/discharge rates.

To improve the reversible charge/discharge performance of the spray-printed honeycomb CNF electrode, especially at high-rate conditions where structural advantages of the honeycomb electrode were more significant, adding a minor fraction of $\mathrm{Si}$, which is an intrinsically high-energy-density $\mathrm{Li}$ insertion material $(\sim 4200 \mathrm{mAh} / \mathrm{g}),{ }^{50,51}$ was examined. Figure 7 a presents a schematic of the intended microstructure comprising bundles of CNFs decorated with Si particles in a honeycomb electrode. Figure $7 \mathrm{~b}$ shows an SEM image of the corresponding spray-printed CNF-based electrode in which 200-400 nm Si particles were decorated over the CNFs, which maintained the fibrous honeycomb structure of the CNF-only 

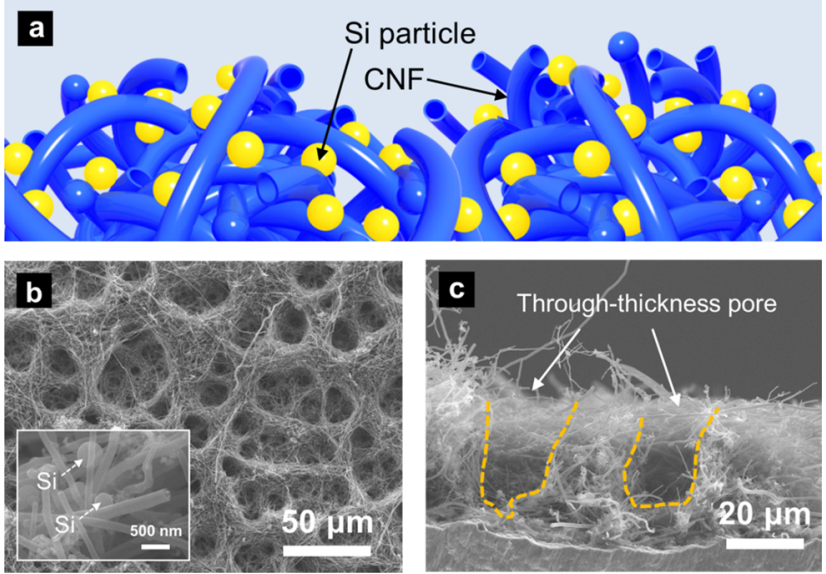

Figure 7. (a) Graphical illustration of the idealized spray-printed Sidecorated CNF structure. (b) Plan view SEM image of the surface of spray-printed fibrous honeycomb CNF electrode containing $\mathrm{Si}$ particulates, with a magnified view in inset. (c) Cross section of the honeycomb CNF $+\mathrm{Si}$ electrode.

electrode already shown in Figure 2. The inset in Figure $7 \mathrm{~b}$ shows at higher magnification that the $\mathrm{Si}$ particles were entangled and attached to the CNFs. The electrode cross section in Figure $7 \mathrm{c}$ again confirmed directional pore channels of approximately $20 \mu \mathrm{m}$ depth.

As shown in the inset bar graph of Figure 8a, as the $\mathrm{Si}$ fraction increased from 0 to $10 \mathrm{wt} \%$, the CNF fraction decreased correspondingly, from 80 to $70 \mathrm{wt} \%$, so the total $\mathrm{CNF}+\mathrm{Si}$ active fraction was fixed at $80 \mathrm{wt} \%$ (refer Table 2). Figure $8 \mathrm{~b}$ shows the deliverable discharge capacity profiles as a function of Si fraction at charge/discharge current densities of $40-8000 \mathrm{~mA} / \mathrm{g}$. At relatively low charge/discharge current densities of 40 and $80 \mathrm{~mA} / \mathrm{g}$, as the $\mathrm{Si}$ fraction increased from
Table 2. Summary of the Spray-Printed Honeycomb CNF Electrodes with Different Si Fractions

\begin{tabular}{cccc}
$\begin{array}{c}\text { Si fraction } \\
(\text { wt \%) }\end{array}$ & $\begin{array}{c}\text { formulation } \\
(\mathrm{CNF} / \mathrm{Si} / \mathrm{SP} / \mathrm{CMC})\end{array}$ & $\begin{array}{c}\text { thickness } \\
(\mu \mathrm{m})\end{array}$ & $\begin{array}{c}\text { mass loading } \\
\left(\mathrm{mg} / \mathrm{cm}^{2}\right)\end{array}$ \\
0.0 & $80.0: 0: 10: 10$ & $20 \pm 3$ & $0.95 \pm 0.04$ \\
2.5 & $77.5: 2.5: 10: 10$ & $20 \pm 4$ & $0.96 \pm 0.04$ \\
5.0 & $75.0: 5.0: 10: 10$ & $20 \pm 2$ & $1.01 \pm 0.05$ \\
10.0 & $70.0: 10.0: 10: 10$ & $20 \pm 4$ & $1.05 \pm 0.03$ \\
\hline
\end{tabular}

0 to $10 \mathrm{wt} \%$, the electrode discharge capacities increased progressively, showing the effectiveness of even only minor fractions of high-capacity $\mathrm{Si}$. However, with increasing charge/ discharge current density up to $8000 \mathrm{~mA} / \mathrm{g}$, the contribution of the $\mathrm{Si}$ became less marked and the lower Si fractions retained capacity better. For example, discharge capacities of a CNF + 10 wt \% Si electrode, which had the highest discharge capacity at 40 and $80 \mathrm{~mA} / \mathrm{g}$, had the lowest discharge capacity at 8000 $\mathrm{mA} / \mathrm{g}$ and even lower than that of a CNF-only electrode, suggesting that the Si had become fragmented and electrically isolated within the electrode due to its large volume expansion and pulverization at ultrafast lithiation/delithiation conditions, then contributing only to parasitic mass, as reported often in other similar Si-incorporating composite electrodes. ${ }^{52,53}$

The $\mathrm{CNF}+2.5$ wt $\% \mathrm{Si}$ electrode retained the highest discharge capacity in the range of $800-8000 \mathrm{~mA} / \mathrm{g}$, for example, $\sim 170 \mathrm{mAh} / \mathrm{g}$ at $4000 \mathrm{~mA} / \mathrm{g}$ and $\sim 120 \mathrm{mAh} / \mathrm{g}$ at $8000 \mathrm{~mA} / \mathrm{g}$. The galvanostatic charge/discharge profiles in the inset of Figure $8 \mathrm{~b}$ show rate performance behavior at 8000 $\mathrm{mA} / \mathrm{g}:$ the $\mathrm{CNF}+2.5 \mathrm{wt} \% \mathrm{Si}$ electrode had the highest discharge capacity, whereas the CNF + $10 \mathrm{wt} \% \mathrm{Si}$ electrode had the lowest. The performance of a spray-printed Si-only electrode was investigated at increasing current densities of $40-8000 \mathrm{~mA} / \mathrm{g}$, as shown in Table S1 and Figure S4 in the Supporting Information. At $40-200 \mathrm{~mA} / \mathrm{g}$, the Si-only
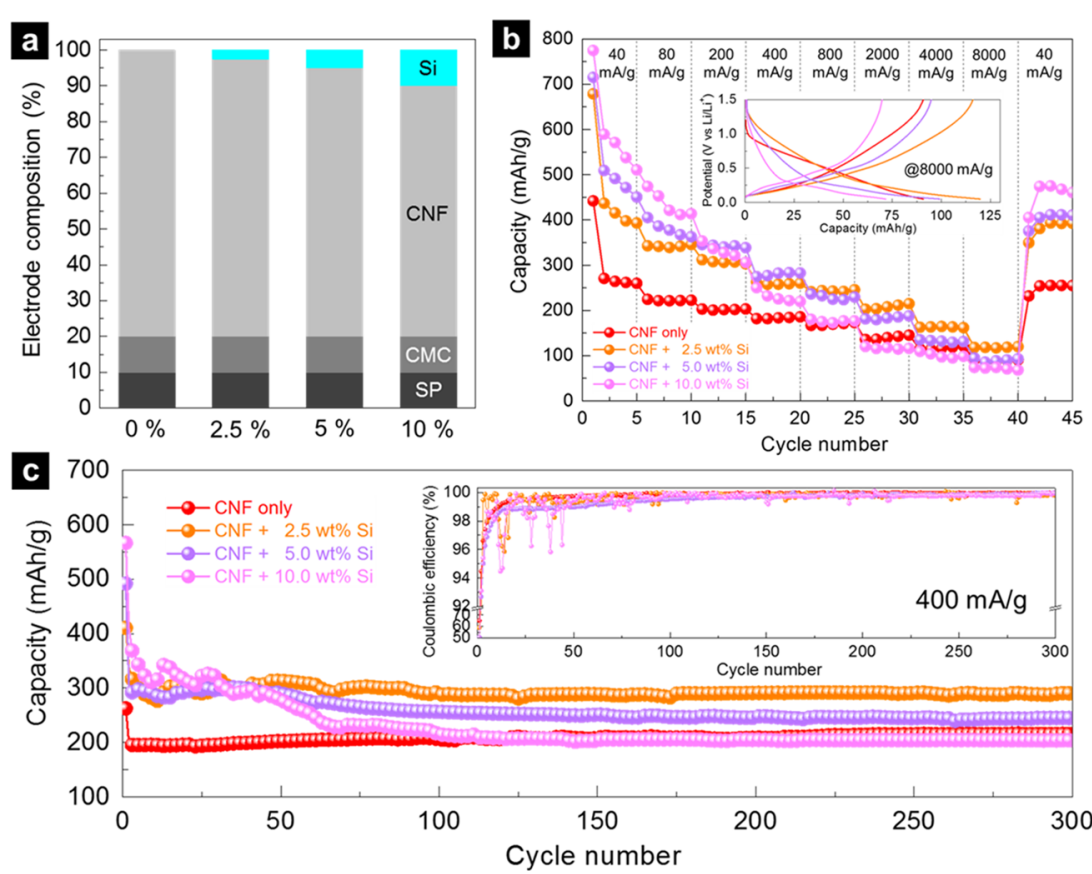

Figure 8. (a) Summary of the Si fraction in the spray-printed honeycomb CNF electrodes. (b) Discharge capacity plots of the fibrous honeycomb CNF electrodes with Si fractions of $0-10 \mathrm{wt} \%$ at various charge/discharge current densities in the potential range of $0.05-1.5 \mathrm{~V}\left(\mathrm{vs} \mathrm{Li} / \mathrm{Li}{ }^{+}\right)$. The inset exhibits charge/discharge plots of the electrodes with different $\mathrm{Si}$ fractions at $8000 \mathrm{~mA} / \mathrm{g}$. (c) Galvanostatic discharge plots at $400 \mathrm{~mA} / \mathrm{g}$ in the voltage window of $0.05-1.5 \mathrm{~V}\left(\mathrm{vs} \mathrm{Li} / \mathrm{Li}^{+}\right)$. The inset shows the corresponding coulombic efficiency of each electrode. 
Table 3. Summary of the Full Spray-Printed LIBs with CNF-Based Anodes and LFP-Based Cathodes

\begin{tabular}{|c|c|c|c|c|c|c|}
\hline \multirow[b]{2}{*}{ electrode } & \multicolumn{3}{|c|}{ mass loading $\left(\mathrm{mg} / \mathrm{cm}^{2}\right)$} & \multicolumn{3}{|c|}{ discharge capacity $(\mathrm{mAh} / \mathrm{g})$} \\
\hline & anode & cathode & $40 \mathrm{~mA} / \mathrm{g}$ & $400 \mathrm{~mA} / \mathrm{g}$ & $2 \mathrm{~A} / \mathrm{g}$ & $4 \mathrm{~A} / \mathrm{g}$ \\
\hline CNF-only & $0.95 \pm 0.04$ & $2.07 \pm 0.03$ & 180 & 150 & 130 & 115 \\
\hline $\mathrm{CNF}+2.5$ wt $\% \mathrm{Si}$ & $0.96 \pm 0.03$ & $2.64 \pm 0.04$ & 280 & 225 & 175 & 150 \\
\hline
\end{tabular}
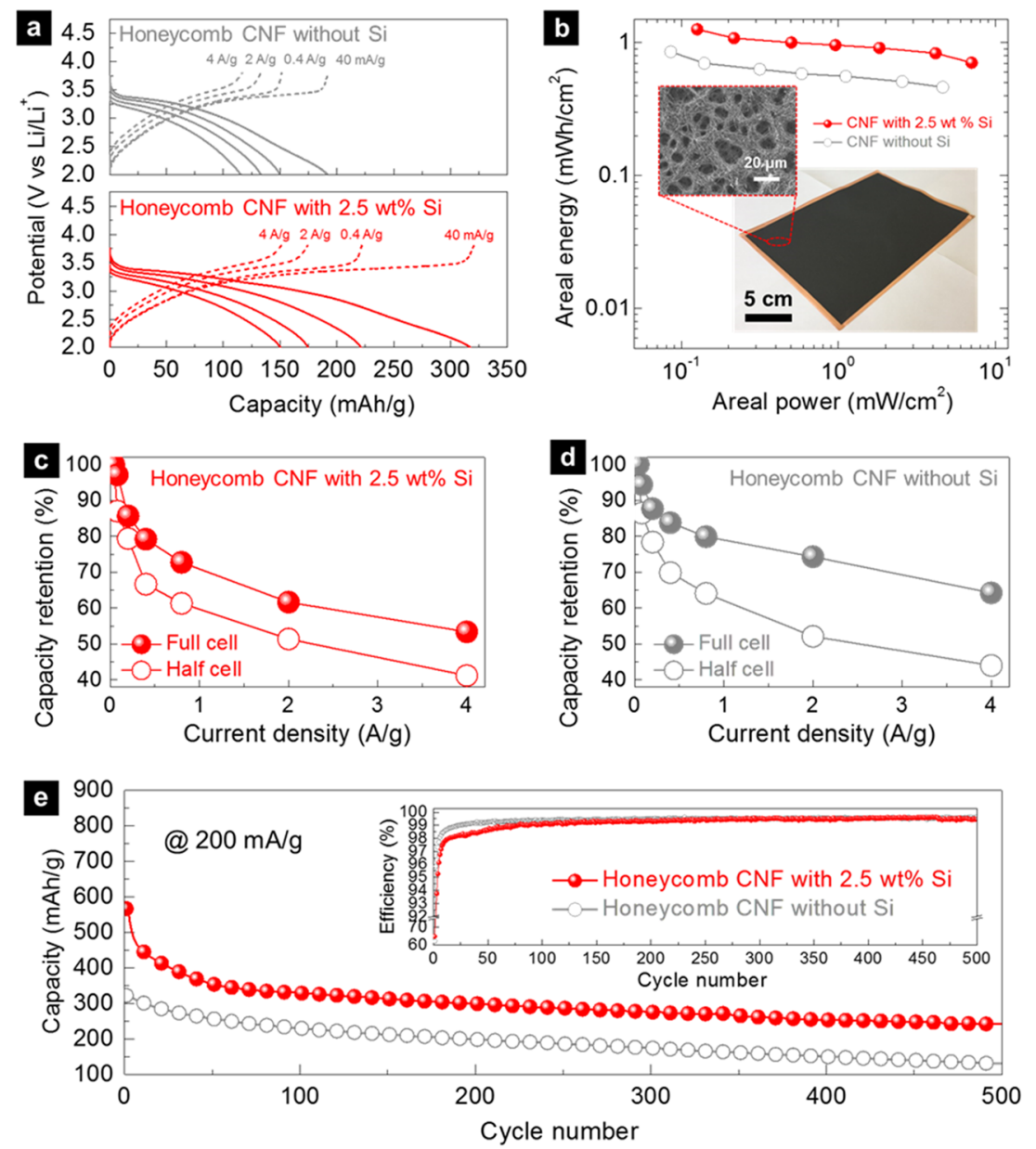

Figure 9. (a) Charge/discharge plots of full-cell batteries with honeycomb CNF electrodes with and without 2.5 wt \% Si at different current densities of $40-4000 \mathrm{~mA} / \mathrm{g}$ in the voltage window of $2.0-3.8 \mathrm{~V}$ (vs $\left.\mathrm{Li} / \mathrm{Li}^{+}\right)$. (b) Ragone plots for the honeycomb CNF electrodes with and without $2.5 \mathrm{wt} \% \mathrm{Si}$. The inset photograph showing an A5-scale spray-printed CNF $+2.5 \mathrm{wt} \% \mathrm{Si}$ electrode on a Cu current collector. Magnified plan view SEM image of the surface of the fibrous honeycomb electrode. Comparative capacity retention profiles of full cells and half-cells for the spray-printed honeycomb CNF electrodes (c) with and (d) without $2.5 \mathrm{wt} \% \mathrm{Si}$. (e) Galvanostatic full-cell discharge plots at $200 \mathrm{~mA} / \mathrm{g}$ in the voltage window of $2.0-3.8 \mathrm{~V}\left(\mathrm{vs} \mathrm{Li} / \mathrm{Li}^{+}\right)$for the $\mathrm{CNF}+2.5 \mathrm{wt} \% \mathrm{Si}$ and CNF-only electrode. The inset shows the corresponding coulombic efficiency of each electrode.

electrode had discharge capacities higher than $1000 \mathrm{mAh} / \mathrm{g}$ but capacity catastrophically collapsed as C-rates increased progressively up to $8000 \mathrm{~mA} / \mathrm{g}$. Eventually, the capacity reduced almost to zero at $8000 \mathrm{~mA} / \mathrm{g}$. By contrast, at 8000 $\mathrm{mA} / \mathrm{g}$, the $\mathrm{CNF}+2.5 \mathrm{wt} \% \mathrm{Si}$ electrode had a higher discharge capacity than that of the CNF-only electrode, suggesting that mechanical compliance in the CNF structure and the multiscale pores were effective in mitigating volume expansion effects and $\mathrm{Si}$ pulverization even at fast charge/discharge rates.

In the galvanostatic discharge plots at $400 \mathrm{~mA} / \mathrm{g}$ in Figure $8 c$, a fibrous honeycomb CNF +2.5 wt \% Si electrode sustained the highest discharge capacity of $\sim 290 \mathrm{mAh} / \mathrm{g}$ after 300 cycles, showing an approximately $40 \%$ improvement in deliverable discharge capacity over a CNF-only honeycomb electrode without Si. CNF electrodes with 5 and 10 wt \% Si had lower discharge capacities of $\sim 240$ and $\sim 200 \mathrm{mAh} / \mathrm{g}$, respectively. The Si particles in the honeycomb CNF $+2.5 \mathrm{wt}$ $\% \mathrm{Si}$ electrode were estimated to have $\sim 340 \%$ volume expansion after 300 cycles, as shown in Figure S5 in the Supporting Information. In the inset of Figure 8c, the CNF + 10 wt \% Si electrode showed the lowest coulombic efficiency of $45 \%$ in the $1^{\text {st }}$ charge/discharge cycle, which, as previously described, was likely associated with a loss of irreversible capacities from SEI formation on $\mathrm{Si}$ and CNF surfaces; however, excluding the first few cycles, all electrodes recovered and sustained a coulombic efficiency of almost $100 \%$ up to the 300th cycle.

The honeycomb negative electrode with 2.5 wt \% Si was further investigated in full-cell configurations with a nonhoneycomb spray-printed LFP positive electrode, to investigate 
any electrochemical benefits of the honeycomb structure in the CNF (refer to the half-cell performance of the spray-printed LFP electrode in Figure S6 and Table S2 in the Supporting Information). The CNF-LFP LIB configuration was constructed with a balanced 1:1 anode/cathode capacity ratio (see Table 3) that delivers the best performance in energy density and power density. ${ }^{54} \mathrm{~A}$ Si-containing honeycomb negative electrode was also compared with the equivalent electrode without $\mathrm{Si}$ in full LIB arrangements (see Figure S8 in the Supporting Information).

Figure 9a shows the galvanostatic charge/discharge profiles of the CNF + Si/LFP and CNF-only/LFP full cells at charge/ discharge current densities of $40-4000 \mathrm{~mA} / \mathrm{g}$. The CNF +2.5 wt $\% \mathrm{Si}$ electrode had much higher charge/discharge capacities than those of the CNF-only electrode at all current densities, with discharge capacities of $\sim 320 \mathrm{mAh} / \mathrm{g}$ at $40 \mathrm{~mA} / \mathrm{g}, \sim 220$ $\mathrm{mAh} / \mathrm{g}$ at $400 \mathrm{~mA} / \mathrm{g}$, and $\sim 150 \mathrm{mAh} / \mathrm{g}$ at $4000 \mathrm{~mA} / \mathrm{g}$ (also see comparative performance of spray-printed CNF +2.5 wt \% $\mathrm{Si}$ electrodes with and without the honeycomb in Figure S8 in the Supporting Information). Figure $9 \mathrm{~b}$ presents the Ragone plots of the spray-printed CNF + Si/LFP and CNF-only/LFP full cells at charge/discharge current densities of 40-4000 $\mathrm{mA} / \mathrm{g}$. CNF $+\mathrm{Si} / \mathrm{LFP}$ had an areal energy density of $\sim 1.3$ $\mathrm{mWh} / \mathrm{cm}^{2}$ at $40 \mathrm{~mA} / \mathrm{g}$ and an areal power density of $\sim 7.1$ $\mathrm{mW} / \mathrm{cm}^{2}$ at $4000 \mathrm{~mA} / \mathrm{g}$, whereas CNF-only/LFP had an energy density of $\sim 0.9 \mathrm{mWh} / \mathrm{cm}^{2}$ and a power density of $\sim 4.6$ $\mathrm{mW} / \mathrm{cm}^{2}$ for identical conditions (also see the massnormalized Ragone plots in Figure S7 of the Supporting Information). Note that the positive electrode was not optimized to have the same honeycomb pore structure or CNF network as the negative CNF-based electrode, and thus further performance gains at high charge/discharge conditions might be realizable using both honeycomb positive and negative electrodes.

The inset in Figure 9b shows a photograph of an A5-scale (approximately $20 \mathrm{~cm} \times 15 \mathrm{~cm}$ ) spray-printed honeycomb $\mathrm{CNF}+2.5 \mathrm{wt} \% \mathrm{Si}$ electrode (larger electrode areas are readily available using a larger hot plate) and a magnified SEM image of a portion of the spray-printed A5 electrode, confirming the self-assembled honeycomb pore pattern over large areas.

It is worth noting that the benefits of the honeycomb pore structure were realized more significantly and more effectively in the full-cell arrangement, where Li-ion supply is finite, rather than in the half-cell arrangement with $\mathrm{Li}$ foil where $\mathrm{Li}$-ion availability is essentially unrestricted. Figure $9 \mathrm{c}, \mathrm{d}$ shows the rate capacity profiles of half-cell and full-cell configurations at different current densities. Here, the rate capacity retention is defined as the ratio of the discharge capacity obtained at 40 , $80,200,400,800,2000$, and $4000 \mathrm{~mA} / \mathrm{g}$ to the discharge capacity at $40 \mathrm{~mA} / \mathrm{g}$. Both CNF-only and CNF $+\mathrm{Si}$ in full cells with LFP outperformed identical half-cells with $\mathrm{Li}$ foil at all current densities (Figure 9c,d), with 30 and $45 \%$ improvements in the capacity retention at $4000 \mathrm{~mA} / \mathrm{g}$, respectively. Slightly lower capacity but better capacity retention arose because there was, in general, a lower Li-ion concentration in the full cell and therefore less intercalation and less electrode damage and any volumetric changes were better tolerated, especially in the more mechanically compliant, higher porosity honeycomb electrode. Figure $9 \mathrm{e}$ shows the galvanostatic discharge capacity profiles of CNF + Si/LFP and CNF-only/ LFP full cells at $200 \mathrm{~mA} / \mathrm{g}$. The $\mathrm{CNF}+\mathrm{Si}$ and CNF-only electrodes sustained a discharge capacity of $\sim 240$ and $\sim 130$ $\mathrm{mAh} / \mathrm{g}$ after 500 cycles, respectively. Both the electrodes had a coulombic efficiency of almost $100 \%$ after 500 cycles excluding the few initial cycles (the inset in Figure 9e).

\section{CONCLUSIONS}

Fibrous honeycomb electrodes of CNFs with micron-scale through-thickness pores were manufactured directly on current collectors using a layer-by-layer spray-printing process based on bisolvent fugitive carriers containing DI water and IPA. The conditions for the formation of the honeycomb structure were identified to depend on the volume ratio of the DI/IPA bisolvent carrier and the current collector temperature. The self-assembly of honeycomb pores occurred only at a current collector temperature of $120{ }^{\circ} \mathrm{C}$, high enough to evaporate the liquid bisolvent carrier that was formulated in an optimum volume ratio of 50:50 DI/IPA. At low current densities, CNFbased electrode gravimetric and volumetric capacities were low. However, through-thickness pore channels promoted efficient Li-ion dynamics throughout the electrode as current density increased, leading to marked overall improvements in capability and cycling performance.

Incorporating an optimum fraction of $2.5 \mathrm{wt} \% \mathrm{Si}$ onto CNFs boosted the honeycomb CNF electrode performance in the fast charge/discharge $800-8000 \mathrm{~mA} / \mathrm{g}$ region further, which was realized most markedly in a full-cell configuration where the CNF-based electrode served as the negative electrode and a spray-printed LFP electrode was used as the positive electrode. The material combination used here is a model system to demonstrate the generic possibilities of how large area, directional, and beneficial micron-scale honeycomb pore structures can be spray-printed directly on current collectors to better realize the intrinsic properties of energy storage materials at high charge/discharge rates.

\section{EXPERIMENTAL SECTION}

Materials. CNFs were obtained from Sigma-Aldrich, U. K.; Si particles were purchased from Alfa Aesar, U. K.; and LFP particles were obtained from Hydro-Québec, Canada.

Spray-Printing Process. Prior to spray-printing, active materials $(\mathrm{CNF}$ or $\mathrm{CNF}+\mathrm{Si})$, SP conductivity enhancers, and CMC binders in a controlled mass ratio of 80:10:10 (these relatively high concentrations of inactive components are typical of CNF-based electrodes where an open, porous structure is preferred, although inactive fractions have been successfully minimized to $5 \%$ or less in other spray-printed electrodes ${ }^{54}$ ) were suspended into a mixture of DI water and IPA using ultrasonication for $30 \mathrm{~min}$. A current collector was fixed on a vacuum chuck of a hot plate that was maintained at temperatures in the range of $60-120^{\circ} \mathrm{C}$. The CNF-based suspensions were then atomized through a spray nozzle at an air pressure of 0.4 bar (see Figure 1). The entire spray process was carried out in a wellventilated fume cupboard.

Electrochemical Testing. The electrochemical performance of the spray-printed electrodes was examined using coin cells (CR2032) assembled from thoroughly dried electrodes in an Ar-filled glovebox $\left(\mathrm{H}_{2} \mathrm{O}<0.1 \mathrm{ppm}, \mathrm{O}_{2}<0.1 \mathrm{ppm}\right)$. For half-cells, the working electrode was assembled with pure Li chips (99.9\% trace metals basis, MTI Corporation) as the counter/reference electrode. In the manufacture of full LIBs, spray-printed CNF-based anodes (e.g., CNF-only or CNF $+2.5 \mathrm{wt} \% \mathrm{Si}$ ) were coupled with spray-printed LFP cathodes that were formulated with a 80:10:10 mass ratio of LFP/SP/CMC for an optimum capacity balance between anodes and cathodes. The anodes and cathodes were electrically separated by a polyethylene separator (Cellgard 2400) soaked into $1 \mathrm{M} \mathrm{LiPF}_{6}$ electrolyte solution in a 1:1 mixture (by volume) of ethylene carbonate and dimethyl carbonate (Merck). Galvanostatic charge/discharge tests for both half-cells and full LIBs were carried out at room temperature using an Arbin battery cycler (Arbin BT2000). Although charge/discharge capacity values of 
half-cells were calculated using the mass of active materials (e.g., $\mathrm{CNF}, \mathrm{CNF}+\mathrm{Si}$, or LFP), full LIB capacities were estimated on the basis of the weight of the active materials in the anode (e.g., CNF or $\mathrm{CNF}+\mathrm{Si}$ ). The theoretical capacity of CNF and LFP was assumed to be $\sim 370 \mathrm{mAh} / \mathrm{g}^{48,49}$ and $\sim 170 \mathrm{mAh} / \mathrm{g}, 5,56$ respectively.

\section{ASSOCIATED CONTENT}

\section{S Supporting Information}

The Supporting Information is available free of charge on the ACS Publications website at DOI: 10.1021/acsami.8b15164.

SEM images of the pristine CNF structures; magnified SEM images of the spray-printed CNF-based electrode; summary of the spray-printed Si-only electrode; discharge capacity plots of the Si-only, CNF-only, and $\mathrm{CNF}+2.5 \mathrm{wt} \% \mathrm{Si}$ electrodes; volume expansion of $\mathrm{Si}$ after 300 cycles; performances of the spray-printed LFPbased electrode; summary of the spray-printed LFPbased electrode; mass-based Ragone plots; comparative charge/discharge plots for full LIBs of spray-printed $\mathrm{CNF}+2.5$ wt $\% \mathrm{Si}$ electrodes with and without the honeycomb (PDF)

\section{AUTHOR INFORMATION}

\section{Corresponding Author}

*E-mail: sangho.lee@materials.ox.ac.uk.

\section{ORCID}

Sang Ho Lee: 0000-0002-2546-5598

\section{Funding}

This work was supported by the U. K. Engineering and Physical Science Research Council grant EP/M009394, "ELEctrochemical Vehicle Advanced TEchnology (ELEVATE)".

\section{Notes}

The authors declare no competing financial interest.

\section{ACKNOWLEDGMENTS}

The authors would like to thank Hydro-Québec for providing $\mathrm{LiFePO}_{4}$ materials.

\section{REFERENCES}

(1) Shi, G.; Kioupakis, E. Electronic and Optical Properties of Nanoporous Silicon for Solar-Cell Applications. ACS Photonics 2015, 2, 208-215.

(2) Rajabi, M.; Dariani, R. S. Current improvement of Porous Silicon Photovoltaic Devices by Using Double Layer Porous Silicon Structure: Applicable in Porous Silicon Solar Cells. J. Porous Mater. 2009, 16, 513-519.

(3) Butler, K. T.; Hendon, C. H.; Walsh, A. Designing Porous Electronic Thin-Film Devices: Band Offsets and Heteroepitaxy. Faraday Discuss. 2017, 201, 207-219.

(4) Jeong, G. S.; Baek, D.-H.; Jung, H. C.; Song, J. H.; Moon, J. H.; Hong, S. W.; Kim, I. Y.; Lee, S.-H. Solderable and Electroplatable Flexible Electronic Circuit on a Porous Stretchable Elastomer. Nat. Commun. 2012, 3, No. 977.

(5) Li, T.; Li, L.; Sun, H.; Xu, Y.; Wang, X.; Luo, H.; Liu, Z.; Zhang, T. Porous Ionic Membrane Based Flexible Humidity Sensor and Its Multifunctional Applications. Adv. Sci. 2017, 4, No. 1600404.

(6) Wales, D. J.; Grand, J.; Ting, V. P.; Burke, R. D.; Edler, K. J.; Bowen, C. R.; Mintovab, S.; Burrows, A. D. Gas Sensing Using Porous Materials for Automotive Applications. Chem. Soc. Rev. 2015, 44, 4290-4321.

(7) Lehman, S. E.; Mudunkotuwa, I. A.; Grassian, V. H.; Larsen, S. C. Nano-Bio Interactions of Porous and Nonporous Silica Nanoparticles of Varied Surface Chemistry: A Structural, Kinetic, and Thermodynamic Study of Protein Adsorption from RPMI Culture Medium. Langmuir 2016, 32, 731-742.

(8) Harraz, F. A. Porous Silicon Chemical Sensors and Biosensors: a Review. Sens. Actuators, B 2014, 202, 897-912.

(9) Qi, J.; Zhang, W.; Cao, R. Porous Materials as Highly Efficient Electrocatalysts for the Oxygen Evolution Reaction. ChemCatChem 2018, 10, 1206-1220.

(10) Lee, S. H.; Park, W.; Lee, B. H.; Kim, W. B. Patterned Catalyst Arrays of $\mathrm{Pd} / \mathrm{SnO}_{2}$ Core-Shell Nanowires for Electrooxidations of Biomass-derived Alcohols. J. Mater. Chem. A 2015, 3, 13492-13499.

(11) He, Y.; Bai, S.; Chang, Z.; Li, Q.; Qiao, Y.; Zhou, H. Porous Hybrid Aerogels with Ultrahigh Sulfur Loading for Lithium-Sulfur Batteries. J. Mater. Chem. A 2018, 6, 9032-9040.

(12) Xiao, J.; Mei, D.; Li, X.; Xu, W.; Wang, D.; Graff, G. L.; Bennett, W. D.; Nie, Z.; Saraf, L. V.; Aksay, I. A.; Liu, J.; Zhang, J.-G Hierarchically Porous Graphene as a Lithium-Air Battery Electrode. Nano Lett. 2011, 11, 5071-5078.

(13) Li, A.; He, R.; Bian, Z.; Song, H.; Chen, X.; Zhou, J. Enhanced Lithium Storage Performance of Hierarchical $\mathrm{CuO}$ Nanomaterials with Surface Fractal Characteristics. Appl. Surf. Sci. 2018, 443, 382388.

(14) Chen, Y.; Shi, L.; Guo, S.; Yuan, Q.; Chen, X.; Zhou, J.; Song, H. A General Strategy towards Carbon Nanosheets from Triblock Polymers as High-Rate Anode Materials for Lithium and Sodium Ion Batteries. J. Mater. Chem. A 2017, 5, 19866-19874.

(15) Huang, C.; Young, N. P.; Zhang, J.; Snaith, H. J.; Grant, P. S. A Two Layer Electrode Structure for Improved Li Ion Diffusion and Volumetric Capacity in Li Ion Batteries. Nano Energy 2017, 31, 377385.

(16) Vu, A.; Qian, Y.; Stein, A. Porous Electrode Materials for Lithium-Ion Batteries - How to Prepare Them and What Makes Them Special. Adv. Energy Mater. 2012, 2, 1056-1085.

(17) Yu, L.; Wu, B. H.; Lou, X. W. D. Self-Templated Formation of Hollow Structures for Electrochemical Energy Applications. Acc. Chem. Res. 2017, 50, 293-301.

(18) Ren, W.; Wang, Y.; Zhang, Z.; Tan, Q.; Zhong, Z.; Su, F. Carbon-Coated Porous Silicon Composites as High Performance LiIon Battery Anode Materials: Can the Production Process be Cheaper and Greener? J. Mater. Chem. A 2016, 4, 552-560.

(19) Hu, H.; Yu, L.; Gao, X.; Lin, Z.; Lou, X. W. Hierarchical Tubular Structures Constructed from Ultrathin $\mathrm{TiO}_{2}(\mathrm{~B})$ Nanosheets for Highly Reversible Lithium Storage. Energy Environ. Sci. 2015, 8, $1480-1483$

(20) Xiao, L.; Zhao, Y.; Yin, J.; Zhang, L. Clewlike $\mathrm{ZnV}_{2} \mathrm{O}_{4}$ Hollow Spheres: Nonaqueous Sol-Gel Synthesis, Formation Mechanism, and Lithium Storage Properties. Chem. - Eur. J. 2009, 15, 9442-9450.

(21) Wu, C.; Tong, X.; Ai, Y.; Liu, D.-S; Yu, P.; Wu, J.; Wang, Z. M. A Review: Enhanced Anodes of Li/Na-Ion Batteries Based on YolkShell Structured Nanomaterials. Nano-Micro Lett. 2018, 10, No. 40.

(22) Guo, S.; Hu, X.; Hou, Y.; Wen, Z. Tunable Synthesis of YolkShell Porous Silicon@Carbon for Optimizing Si/C-Based Anode of Lithium-Ion Batteries. ACS Appl. Mater. Interfaces 2017, 9, 4208442092.

(23) Li, S.; Niu, J.; Zhao, Y. C.; So, K. P.; Wang, C.; Wang, C. A.; Li, J. High-Rate Aluminium Yolk-Shell Nanoparticle Anode for Li-Ion Battery with Long Cycle Life and Ultrahigh Capacity. Nat. Commun. 2015, 6, No. 7872.

(24) Liu, N.; Wu, H.; McDowell, M. T.; Yao, Y.; Wang, C.; Cui, Y. A Yolk-Shell Design for Stabilized and Scalable Li-Ion Battery Alloy Anodes. Nano Lett. 2012, 12, 3315-3321.

(25) Lu, Y.; Yu, L.; Wu, M.; Wang, Y.; Lou, X. W. Construction of Complex $\mathrm{Co}_{3} \mathrm{O}_{4} @ \mathrm{Co}_{3} \mathrm{~V}_{2} \mathrm{O}_{8}$ Hollow Structures from Metal-Organic Frameworks with Enhanced Lithium Storage Properties. Adv. Mater. 2018, 30, No. 1702875.

(26) Lu, Y.; Nai, J.; Lou, X. W. Formation of $\mathrm{NiCo}_{2} \mathrm{~V}_{2} \mathrm{O}_{8}$ YolkDouble Shell Spheres with Enhanced Lithium Storage Properties. Angew. Chem., Int. Ed. 2018, 57, 2899-2903.

(27) Kim, Y.; Choi, E.; Kim, J. G.; Lee, S.; Yoon, W.; Ham, M.-H.; Kim, W. B. Size-Controlled Hollow Spheres of C $/ \alpha-\mathrm{Fe}_{2} \mathrm{O}_{3}$ Prepared 
via Quasiemulsion-Template Method and Their Electrochemical Properties for Lithium Ion Storage. ChemElectroChem 2017, 4, 20452051.

(28) Kim, D. H.; Oh, D. Y.; Park, K. H.; Choi, Y. E.; Nam, Y. J.; Lee, H. A.; Lee, S.-M; Jung, Y. S. Infiltration of Solution-Processable Solid Electrolytes into Conventional Li-Ion-Battery Electrodes for All-SolidState Li-Ion Batteries. Nano Lett. 2017, 17, 3013-3020.

(29) Ludwig, B.; Zheng, Z.; Shou, W.; Wang, Y.; Pan, H. SolventFree Manufacturing of Electrodes for Lithium-ion Batteries. Sci. Rep. 2016, 6, No. 23150.

(30) Oh, D.; Ozgit-Akgun, C.; Akca, E.; Thompson, L. E.; Tadesse, L. F.; Kim, H.-C; Demirci, G.; Miller, R. D.; Maune, H. Biotemplating Pores with Size and Shape Diversity for Li-Oxygen Battery Cathodes. Sci. Rep. 2017, 7, No. 45919.

(31) Sander, J. S.; Erb, R. M.; Li, L.; Gurijala, A.; Chiang, Y.-M High-Performance Battery Electrodes via Magnetic Templating. Nat. Energy 2016, 1, No. 16099.

(32) Liu, J.; Wang, J.; Kim, J.; Ning, H.; Pan, Z.; Kelly, S. J.; Epstein, E. S.; Huang, X.; Liu, J.; Braun, P. V. High Full-Electrode Basis Capacity Template-Free 3D Nanocomposite Secondary Battery Anodes. Small 2015, 11, 6265-6271.

(33) Pearse, A.; Schmitt, T.; Sahadeo, E.; Stewart, D. M.; Kozen, A.; Gerasopoulos, K.; Talin, A. A.; Lee, S. B.; Rubloff, G. W.; Gregorczyk, K. E. Three-Dimensional Solid-State Lithium-Ion Batteries Fabricated by Conformal Vapor-Phase Chemistry. ACS Nano 2018, 12, 42864294.

(34) Lee, S. H.; Noh, Y.; Kim, W. B. Convex and Concave Square Arrays of Vertical $\mathrm{SnO}_{2}$ Nanowire Bundles toward Lithium-Ion Storage Electrodes. Energy Technol. 2017, 5, 1507-1513.

(35) Ning, H.; Pikul, J. H.; Zhang, R.; Li, X.; Xu, S.; Wang, J.; Rogers, J. A.; King, W. P.; Braun, P. V. Holographic Patterning of High-Performance On-Chip 3D Lithium-Ion Microbatteries. Proc. Natl. Acad. Sci. U. S. A. 2015, 112, 6573-6578.

(36) Lee, S. H.; Mahadevegowda, A.; Huang, C.; Evans, J. D.; Grant, P. S. Spray Printing of Self-Assembled Porous Structures for High Power Battery Electrodes. J. Mater. Chem. A 2018, 6, 13133-13141.

(37) Lee, W.; Park, S.-J Porous Anodic Aluminum Oxide: Anodization and Templated Synthesis of Functional Nanostructures. Chem. Rev. 2014, 114, 7487-7556.

(38) Sole, C.; Drewett, N. E.; Hardwick, L. J. In Situ Raman Study of Lithium-Ion Intercalation into Microcrystalline Graphite. Faraday Discuss. 2014, 172, 223-237.

(39) Spahr, M. E.; Palladino, T.; Wilhelm, H.; Würsig, A.; Goers, D.; Buqa, H.; Holzapfel, M.; Novák, P. Exfoliation of Graphite during Electrochemical Lithium Insertion in Ethylene Carbonate-Containing Electrolytes. J. Electrochem. Soc. 2004, 151, A1383-A1395.

(40) Cheng, Q.; Okamoto, Y.; Tamura, N.; Tsuji, M.; Maruyama, S.; Matsuo, Y. Graphene-Like-Graphite as Fast-Chargeable and HighCapacity Anode Materials for Lithium Ion Batteries. Sci. Rep. 2017, 7, No. 14782.

(41) Cho, S.; Ahn, Y.-K; Yin, Z.; You, D.-J; Kim, H.; Piao, Y.; Yoo, J.; Kim, Y. S. Synthesis of Copper Oxide/Graphite Composite for High-Performance Rechargeable Battery Anode. Chem. - Eur. J. 2017, 23, 11629-11635.

(42) Ko, M.; Chae, S.; Ma, J.; Kim, N.; Lee, H.-W; Cui, Y.; Cho, J. Scalable Synthesis of Silicon-Nanolayer-Embedded Graphite for HighEnergy Lithium-Ion Batteries. Nat. Energy 2016, 1, No. 16113.

(43) Wang, Y.; Xiao, N.; Wang, Z.; Tang, Y.; Li, H.; Yu, M.; Liu, C.; Zhou, Y.; Qiu, J. Ultrastable and High-Capacity Carbon Nanofiber Anodes Derived from Pitch/Polyacrylonitrile for Flexible Sodium-Ion Batteries. Carbon 2018, 135, 187-194.

(44) Li, W.; Li, M.; Adair, K. R.; Sun, X.; Yu, Y. Carbon NanofiberBased Nanostructures for Lithium-Ion and Sodium-Ion Batteries. J. Mater. Chem. A 2017, 5, 13882-13906.

(45) Qie, L.; Chen, W.-M; Wang, Z.-H; Shao, Q.-G; Li, X.; Yuan, L.X; Hu, X.-L; Zhang, W.-X; Huang, Y.-H Nitrogen-Doped Porous Carbon Nanofiber Webs as Anodes for Lithium Ion Batteries with a Superhigh Capacity and Rate Capability. Adv. Mater. 2012, 24, 20472050.
(46) Kim, M.-C; Lee, Y.-W; Kim, S.-J; Hwang, B.-M; Park, H.-C; Hwang, E.-T; Cao, G.; Park, K.-W Improved Lithium Ion Behavior Properties of $\mathrm{TiO}_{2} @$ Graphitic-like Carbon Core@Shell Nanostructure. Electrochim. Acta 2014, 147, 241-249.

(47) Yu, D. Y. W.; Fietzek, C.; Weydanz, W.; Donoue, K.; Inoue, T.; Kurokawa, H.; Fujitani, S. Study of $\mathrm{LiFePO}_{4}$ by Cyclic Voltammetry. J. Electrochem. Soc. 2007, 154, A253-A257.

(48) Paul, R.; Etacheri, V.; Pol, V. G.; Hu, J.; Fisher, T. S. Highly Porous Three-Dimensional Carbon Nanotube Foam as a Freestanding Anode for a Lithium-Ion Battery. RSC Adv. 2016, 6, 7973479744.

(49) Cohn, A. P.; Oakes, L.; Carter, R.; Chatterjee, S.; Westover, A. S.; Share, K.; Pint, C. L. Assessing the Improved Performance of Freestanding, Flexible Graphene and Carbon Nanotube Hybrid Foams for Lithium Ion Battery Anodes. Nanoscale 2014, 6, 46694675.

(50) Wang, M.-S; Song, W.-L; Fan, L.-Z Three-Dimensional Interconnected Network of Graphene-Wrapped Silicon/Carbon Nanofiber Hybrids for Binder-Free Anodes in Lithium-Ion Batteries. ChemElectroChem 2015, 2, 1699-1706.

(51) Dirican, M.; Lu, Y.; Fu, K.; Kizil, H.; Zhang, X. SiO $\mathrm{S}_{2}$-Confined Silicon/Carbon nanofiber Composites as an Anode for Lithium-Ion Batteries. RSC Adv. 2015, 5, 34744-34751.

(52) Lee, J.-I; Ko, Y.; Shin, M.; Song, H.-K; Choi, N.-S; Kim, M. G.; Park, S. High-Performance Silicon-based Multicomponent Battery Anodes Produced via Synergistic Coupling of Multifunctional Coating Layers. Energy Environ. Sci. 2015, 8, 2075-2084.

(53) Whitacre, J. F.; Zaghib, K.; West, W. C.; Ratnakumar, B. V. Dual Active Material Composite Cathode Structures for Li-Ion Batteries. J. Power Sources 2008, 177, 528-536.

(54) Lee, S. H.; Huang, C.; Johnston, C.; Grant, P. S. Spray printing and Optimization of Anodes and Cathodes for High Performance LiIon Batteries. Electrochim. Acta 2018, 292, 546-557.

(55) Zhao, Y.; Peng, L.; Liu, B.; Yu, G. Single-Crystalline LiFePO4 Nanosheets for High-Rate Li-Ion Batteries. Nano Lett. 2014, 14, 2849-2853.

(56) Hu, L.-H; Wu, F.-Y; Lin, C.-T; Khlobystov, A. N.; Li, L.-J Graphene-Modified $\mathrm{LiFePO}_{4}$ Cathode for Lithium Ion Battery beyond Theoretical Capacity. Nat. Commun. 2013, 4, No. 1687. 